\title{
Fabrication and Characterization of Porous CdS/Dye Sensitized Solar Cells
}

\author{
Haider Abdulelah, ${ }^{1}$ Basil Ali, ${ }^{1}$ M. A. Mahdi, ${ }^{1}$ Ali Q. Abdullah, ${ }^{1}$ J. J. Hassan, ${ }^{1}$ \\ H. F. Al-Taay, ${ }^{2}$ and P. Jennings ${ }^{3}$ \\ ${ }^{1}$ Basrah Nanomaterials Research Group (BNRG), Department of Physics, College of Science, University of Basrah, Basrah, Iraq \\ ${ }^{2}$ Department of Physics, College of Science for Women, University of Baghdad, Baghdad, Iraq \\ ${ }^{3}$ School of Engineering and Information Technology, Murdoch University, South St., Murdoch, WA 6150, Australia
}

Correspondence should be addressed to M. A. Mahdi; mazinauny74@yahoo.com

Received 29 March 2016; Accepted 14 August 2016

Academic Editor: Jayasundera M S Bandara

Copyright (C) 2016 Haider Abdulelah et al. This is an open access article distributed under the Creative Commons Attribution License, which permits unrestricted use, distribution, and reproduction in any medium, provided the original work is properly cited.

\begin{abstract}
Dye sensitized solar cells (DSSCs) are fabricated from porous cadmium sulfide (CdS) nanocrystalline thin films. The porous CdS nanostructured thin films are deposited onto FTO/glass substrates by the chemical bath deposition (CBD) method. The surface morphology, crystalline structure, and optical properties of the prepared nanocrystalline thin films are investigated. Rhodamine B, Malachite green, Eosin methylene blue, and Cresyl violet dyes are used to fabricate the DSSC devices. Comparing the absorption spectra of porous CdS nanocrystalline films, all dyes show an absorption peak in the transparent range of CdS thin films indicating that they are suitable for the preparation of DSSCs with CdS. Current-voltage $(I-V)$ characteristics show that the solar cell that is fabricated using Malachite green dye shows the highest conversion efficiency of $0.83 \%$ while using Rhodamine B dye produces a solar cell with lowest efficiency of $0.38 \%$. However, heat treatment of the fabricated solar cells causes significant enhancement in the output of all devices.
\end{abstract}

\section{Introduction}

The world urgently needs alternative sources of environmentally sustainable energy supply for industrial development and electricity supply. Solar power is one of the important clean sources of power, Thus, conversion methods of this power to useful energy have attracted a great deal of attention from scientific researchers and dye-sensitized solar cells (DSSCs) are one of the types of solar cells that show promising properties such as high conversion efficiency, use of environmentally friendly materials, ease of preparation, and low cost of production [1-3]. Nanomaterials are widely used to fabricate solar cells, especially DSSC types, due to their unique physical properties.

Cadmium sulfide (CdS) is an n-type semiconductor with a wide band gap of $2.42 \mathrm{eV}$ (in bulk) that makes it a very suitable semiconductor material for use in preparing optoelectronic devices, especially as a window layer in solar cells $[4,5]$. CdS in nanocrystalline thin films can be prepared by a variety of physical and chemical methods like vacuum evaporation [6], pulsed-laser deposition [7], sol-gel [8], successive ionic layer adsorption and reaction (SILAR) [9], and chemical bath deposition (CBD) [10]. The CBD method produces nanocrystalline, uniform, large area, as well as inexpensive thin films $[4,11]$. CdS nanocrystalline thin films, which are grown by CBD, show important interesting properties. Thus, it is used for electrooptical applications [12]. CdS nanoparticles are used to fabricate DSSCs with different nanomaterials such as $\mathrm{TiO}_{2}$ and $\mathrm{ZnO}$.

Hossain et al. [13] deposited CdS nanoparticles by the CBD method onto nanoporous $\mathrm{TiO}_{2}$ to fabricate DSSCs and they obtained a conversion efficiency of about $1.13 \%$. Mali and coworkers [14] found that the efficiency for $\mathrm{TiO}_{2}$ microspheres covered by CdS nanoparticles reached $2.34 \%$, while Choi et al. [15] obtained 3.14\% from the device that they synthesized, based on $\mathrm{TiO}_{2} / \mathrm{CdS}$ quantum dots. Moreover, Meng et al. [16] prepared devices with $\mathrm{ZnO}$ spheres/CdS quantum dots and obtained an efficiency of about $1.39 \%$. 
The use of porous electrodes in DSSCs is much different to thin films because the inherent conductivity of the film is very low and the small size of the nanocrystalline particles does not support a built-in electrical field. Additionally, porous thin films can help in bringing about ionic conduction when it is in contact with an electrolyte and that led to efficient electrical conductivity in the device [17]. Therefore, using porous electrodes in DSSCs led to efficient transport of photogenerated electrons and this enhances the conversion efficiency. Moreover, the electrolyte penetrates the porous film all the way to the back-contact making the semiconductor/electrolyte interface essentially three-dimensional [18].

In the present work, for the first time, we used porous CdS nanocrstalline thin film as a photoelectrode, instead of $\mathrm{ZnO}$ or $\mathrm{TiO}_{2}$, to fabricate DSSCs using Rhodamine B, Malachite green, Eosin methylene blue, and Cresyl violet perchlorate dyes. The morphology, crystalline structure, and optical and electrical characteristics of the fabricated solar cells were investigated.

\section{Experimental Details}

2.1. Synthesis of CdS Nanocrystalline Thin Films. Fluorinedoped tin oxide (FTO) coated glass substrates with a resistivity of $10 \Omega \cdot \mathrm{cm}^{-1}$ were washed in hot distilled water and then cleaned ultrasonically for 2 minutes using diluted $\mathrm{HCl}$, acetone, ethanol, and isopropanol solutions, respectively. Finally, the substrates were cleaned ultrasonically with distilled water for $5 \mathrm{~min}$ and left to dry naturally.

Porous CdS nanocrystalline thin films were deposited on the FTO/glass substrates using the chemical bath deposition (CBD) method in an alkaline aqueous solution containing $0.05 \mathrm{M}$ of cadmium nitrate $\left[\mathrm{Cd}\left(\mathrm{NO}_{3}\right)_{2}\right]$ and $0.1 \mathrm{M}$ thiourea $\left[\mathrm{CS}\left(\mathrm{NH}_{2}\right)_{2}\right]$. These were used as $\mathrm{Cd}^{2+}$ and $\mathrm{S}^{2-}$ ion source, respectively. Ammonium acetate $\left(\mathrm{NH}_{4} \mathrm{CH}_{3} \mathrm{COO}\right)$ with a concentration of $1 \mathrm{M}$ was added to the solution as a buffer to control the reaction rate. Some drops of ammonia solution (28\%) were added to adjust the $\mathrm{pH}$ of the reaction to 10 and the total volume was $100 \mathrm{~mL}$. After stirring the solution for $5 \mathrm{~min}$, the FTO/glass substrates were immersed vertically in the beaker and then placed on the hot plate under the preparation temperature of $75^{\circ} \mathrm{C}$ for $45 \mathrm{~min}$. Finally, the samples were taken out of the solution and washed by distilled water to remove any contaminants. The preparation process was repeated to increase the thickness of the CdS nanocrystalline thin film. The thickness of the prepared CdS nanocrystalline thin film was $725 \mathrm{~nm}$ and this was calculated using the Swanepoel method [19]. The surface morphology of the obtained CdS nanocrystalline thin films was analyzed by scanning electron microscopy (Zeiss Supra 55VP). Xray diffraction (XRD; PANalytical X'Pert PRO-MRD with CuKa $(1.5406 \AA)$ radiation was employed to determine the crystalline structure of the CdS nanocrystalline thin films. To fabricate a CdS/dyes solar cell, the dye is spread onto the deposited CdS nanocrystalline thin film on FTO/glass. Then the back contact was black carbon spread electrolyte (polysulfide) that is injected between the dye and carbon electrode from a small hole made for this purpose. The current-voltage $(I-V)$ measurement for the devices was investigated before and after heat treatment of the device under various temperatures for $30 \mathrm{~min}$, depending on the type of the dye used. The current-voltage $(I-V)$ measurements were performed using a Keithley2400 source meter in the dark and under the illumination of one sun (AM 1.5, $1000 \mathrm{~W} / \mathrm{m}^{2}$ ).

2.2. Preparation of Electrolyte. A suitable polysulfide liquid electrolyte was developed for the application based on CdS thin film dye-sensitized solar cells (DSSCs). A solvent consisting of methanol and water in the volume ratio of $7: 3$ has been found to be the optimum solvent for preparing the liquid electrolytes [20]. This solvent ratio appears to give a higher conversion efficiency of the solar cell compared with pure methanol or water as a solvent. Furthermore, $\mathrm{Na}_{2} \mathrm{~S}$ and $S$ give rise to a good redox couple in the electrolyte for DSSCs operation, and the optimum concentrations required are $0.5 \mathrm{M}$ and $0.1 \mathrm{M}$, respectively. Addition of potassium chloride $(\mathrm{KCl})$ to the electrolyte further enhances the performance. Then, the solution was stirred for 2 hours. Finally, the solution obtained was kept in the dark to use in DSSC device fabrication.

\section{Principle of DSSC Operation}

Porous n-CdS nanostructured thin film is used as the photoelectrode to fabricate DSSC devices while conductive carbon was used as a counter electrode. Polysulfide electrolyte is injected to fill the space between the porous $\mathrm{CdS}$ photoelectrode and that covered by dye and the counter electrode. When the solar cell is illuminated by light, charge carriers will be generated. Figure 1 shows a scheme of the charge separation process at the Donor:Acceptor interface of a DSSC. At first, light induces the dye to produce photoexcitation into excitons $\left(D^{*}\right)$ as described by the following equation:

$$
\frac{\mathrm{D}}{\mathrm{CdS}}+h v \stackrel{\text { Photo-excitation }}{\longrightarrow} \frac{\mathrm{D}^{*}}{\mathrm{CdS}}
$$

Then, the excitons will migrate and separate at the CdS/dye interface and inject electrons into the conduction band of the $\mathrm{CdS}$ semiconductor, leaving holes $\left(\mathrm{D}^{+}\right)$in the dye as shown by

$$
\frac{\mathrm{D}^{*}}{\mathrm{CdS}} \stackrel{\text { Electron-excitation }}{\longrightarrow} \frac{\mathrm{D}^{+}}{\mathrm{CdS}}+\frac{\mathrm{e}^{-}}{\mathrm{CdS}}
$$

The injection process of electrons from the excited dye molecules to the conduction band of the CdS should be very fast to obtain an efficient DSSC device.

The dye will regenerate by accepting electrons from the reduced state of the redox couple (RE), producing the oxidized state of the redox couple (OX) in the electrolyte:

$$
\frac{\mathrm{D}^{+}}{\mathrm{CdS}}+\mathrm{RE} \stackrel{\text { Dye-regeneration }}{\longrightarrow} \frac{\mathrm{D}}{\mathrm{CdS}}+\mathrm{OX}
$$

After that, electrolyte regeneration occurs via OX accepting electrons from the counter electrode and producing RE:

$$
\mathrm{OX}+\frac{\mathrm{e}^{-}}{\mathrm{CE}} \stackrel{\text { Electrolyte-regeneration }}{\longrightarrow} \mathrm{RE}
$$




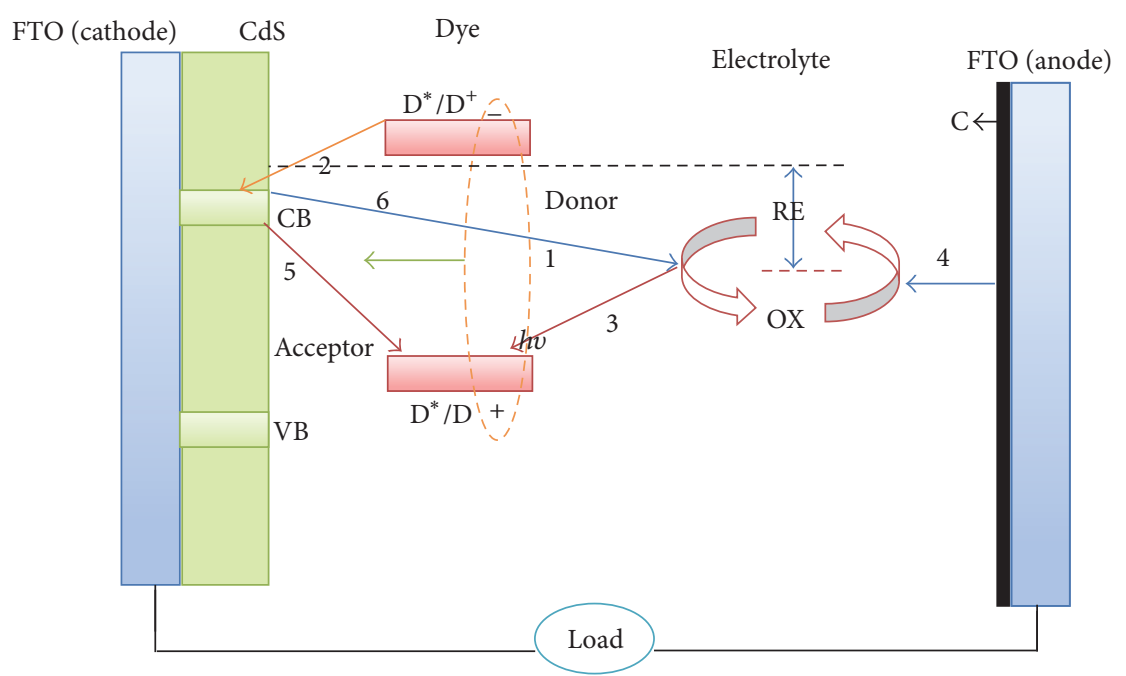

FIGURE 1: Structure and operating principle of CdS/dye-sensitized solar cells. (1) Photo excitation. (2) Electron excitation. (3) Dye regeneration. (4) Electrolyte regeneration. (5) Recombination by $\mathrm{D}^{+}$. (6) Recombination by OX.

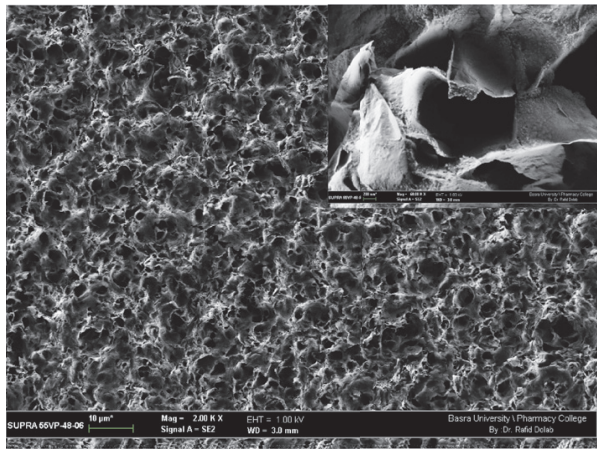

(a)

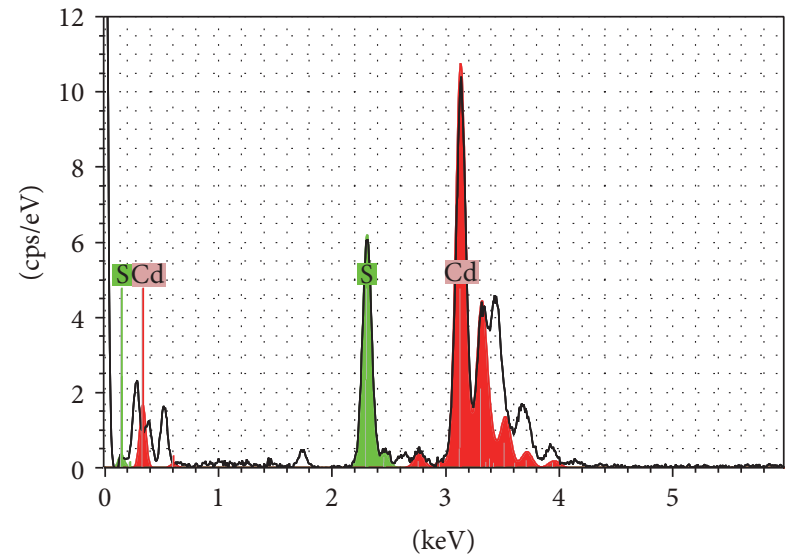

(b)

FIGURE 2: (a) FE-SEM micrograph of porous CdS nanocrystalline thin film, inset high magnification of thin film, (b) EDX spectra of porous CdS nanocrystalline thin film.

The injecting electrons will recombine by donating electrons to $\mathrm{D}^{+}$:

$$
\frac{\mathrm{e}^{-}}{\mathrm{CdS}}+\frac{\mathrm{D}^{+}}{\mathrm{CdS}} \stackrel{\text { Recombination-by- } \mathrm{D}^{+}, \text {Dark-reaction }}{\longrightarrow} \frac{\mathrm{D}}{\mathrm{CdS}}
$$

Finally, the injected electrons recombine by donating electrons to OX:

$$
\frac{\mathrm{e}^{-}}{\mathrm{CdS}}+\mathrm{OX} \stackrel{\text { Recombination-by-OX,Dark-reaction }}{\longrightarrow} \mathrm{RE}
$$

Fast photogeneration of electrons and translation from the conduction band of CdS to the FTO electrode is very important to obtain an efficient DSSC device. It is worth mentioning that $\mathrm{CdS}$ is toxic, especially when inhaled as dust, but we can avoid this danger by following laboratory safety instructions.

\section{Results and Discussion}

4.1. Surface Morphology. Figure 2 shows the FE-SEM images of a prepared CdS nanocrystalline thin film. The CdS is grown on the surface of FTO-glass substrate as a porous structure. The pores with different diameters are distributed over the surface of the CdS thin film that covers the entire area of the substrate. The type of nanostructure prepared by the CBD method can be controlled by adjusting the synthesis parameters such as molar concentration, temperature, rate of deposition, and the type of substrate [11]. Two ideas have been proposed for describing the mechanism of synthesis of thin films by the CBD method: they are ion-by-ion and cluster. However, according to the ion-by-ion mechanism, the $\mathrm{Cd}^{2+}$ and $\mathrm{S}^{2-}$ ions are absorbed on the surface of the substrate and then combine to form CdS nanoparticles that act as seeds to grow the nanostructure. Gosavi et al. [17] suggested that the CdS nanoparticles will aggregate together to form a uniform layer which in turn led to the formation of 
TABLE 1: Output of as-prepared porous CdS nanocrystalline thin films/dyes DSSCs.

\begin{tabular}{lccccc}
\hline Dye & $J_{\mathrm{sc}}\left(\mathrm{mA} / \mathrm{cm}^{2}\right)$ & $V_{\mathrm{oc}}(\mathrm{mV})$ & $R_{\mathrm{sh}}(\Omega)$ & $R_{s}(\Omega)$ & \multicolumn{1}{c}{$\eta^{2} \%$} \\
\hline Rhodamine B & 4.7 & 245.5 & 1257 & 507 & 33 \\
Malachite green & 5.7 & 405 & 1930 & 594 & 35 \\
Eosin methylene blue & 4.2 & 385.9 & 1561 & 1017 & 0.38 \\
Cresyl Violet & 3.1 & 500.3 & 3495 & 1235 & 33 \\
\hline
\end{tabular}

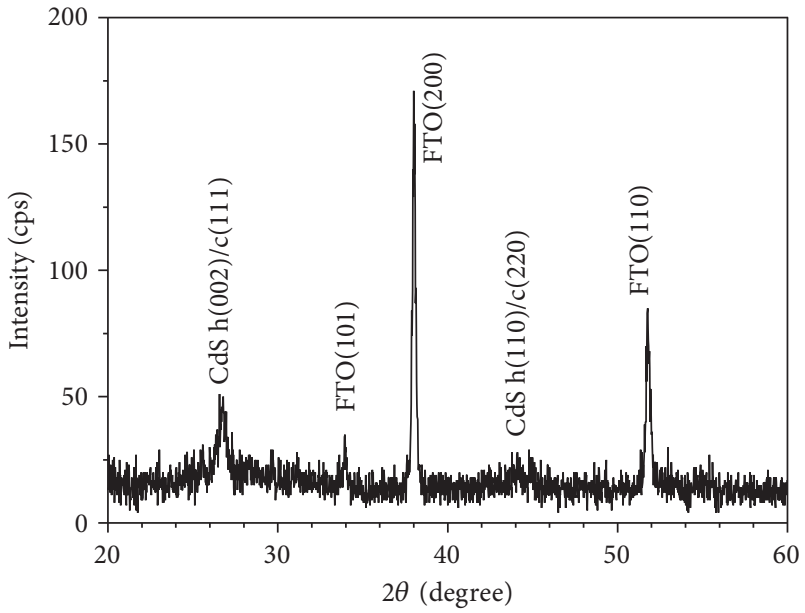

FIGURE 3: XRD pattern of porous CdS nanocrystalline thin film prepared onto FTO/glass substrate.

a porous nanostructure. Figure 2 inset shown in the FE-SEM micrograph of the prepared sample at higher magnification shows clearly that the $\mathrm{CdS}$ nanolayers- or nanowalls-like structure are organized and surround the pores as the porous nanostructure is formed. It is worth mentioning that porous materials are very interesting nanostructures that are used to fabricate optoelectronic devices, especially solar cells. Energy dispersive X-ray (EDX) analysis showed that the ratio of cadmium to sulfur $(\mathrm{Cd} / \mathrm{S})$ in porous $\mathrm{CdS}$ nanocrystalline thin films was 1.42 (Figure 2(b)).

4.2. Crystalline Structure. The crystalline structure of the prepared porous CdS nanocrystalline thin film was investigated by the XRD method as shown in Figure 3. The XRD pattern contains diffraction peaks corresponding to (101), (200), and (110) planes of the FTO-glass substrate and other peaks are related to the $\mathrm{CdS}$ structure. However, the diffraction peaks located at $26.64^{\circ}$ could be related to the (111) plane of CdS cubic (zincblende) structure or to the hexagonal (wurtzite) phase of CdS according to the standard data base PDF-4 (00-001-0647 and 00-001-0780). In addition, the diffraction peak at $44.08^{\circ}$ could correspond to the $\mathrm{c}(220)$ or $\mathrm{h}(110)$ plane. The close location of the diffraction peaks of the cubic and hexagonal phases of $\mathrm{CdS}$ makes it difficult to determine the structure type, but the absence of (101) and (100) hexagonal planes may indicate that the crystalline structure of the CdS porous thin film is zincblende [4].

4.3. Optical Properties. Figure 4(a) shows the UV-Vis absorbance and reflectance spectra of the prepared porous
CdS nanocrystalline thin films on the FTO/glass substrate. The absorption edge was observed around the wavelength of $495 \mathrm{~nm}(2.5 \mathrm{eV})$, and the prepared thin films appeared to have a low reflection value $(\sim 0.5 \%)$ for the wavelength range of $500-700 \mathrm{~nm}$. The optical absorption of the dyes is shown in Figure 4(b). Comparing with the absorption spectrum of CdS nanocrystalline films, all dyes show absorption peaks in the transparent range of $\mathrm{CdS}$. The absorption peaks of $548,580,620$, and $650 \mathrm{~nm}$ can be absorbed by the dyes, Rhodamine B, Cresyl violet, Malachite green, and Eosin, respectively. The optical band gap $\left(E_{q}\right)$ of porous CdS nanocrystalline thin film is calculated from the reflection spectrum using the relationship [21]:

$$
2 \alpha d=\ln \left[\frac{R_{\max }-R_{\min }}{R-R_{\min }}\right],
$$

where $\alpha$ is absorption coefficient, $d$ is the thickness of thin film, $R$ is the reflectance at any wavelength, and $R_{\max }$ and $R_{\min }$ are the maximum and minimum values of the reflectance. Thus, the optical band gap can be estimated from Figure 5 in which the square of $h v\left\{\ln \left[\left(R_{\max }-R_{\min }\right) /(R-\right.\right.$ $\left.\left.\left.R_{\text {min }}\right)\right]\right\}$ is plotted against $h v$. The absorption coefficient $(\alpha)$ increases sharply with photon energy beyond the absorption edge. The calculated optical band gap of the prepared CdS nanocrystalline thin film is $2.51 \mathrm{eV}$ and is higher than that for bulk CdS of $2.42 \mathrm{eV}$ [22]. The increase in the optical band gap of the prepared porous CdS thin film can be related to the quantum size effect that appears in nanocrystalline structures [23]. The optical properties of the CdS nanocrystalline thin films indicate that they are suitable for use in fabricating DSSCs.

4.4. J-V Characteristics. Figure 6 shows the current densityvoltage characteristics of as-fabricated solar cells under illumination. The porous $\mathrm{CdS} / \mathrm{Cresyl}$ violet device shows the highest open circuit voltage $\left(V_{\mathrm{oc}}\right)$ of $500.3 \mathrm{mV}$ while the CdS/Rhodamine B was the lowest $V_{\text {oc }}$ of $245.5 \mathrm{mV}$. In addition, the DSSC prepared on porous CdS/Malachite green gave the highest value of $J_{\mathrm{sc}}$ of $5.7 \mathrm{~mA} / \mathrm{cm}^{2}$ in contrast to the $\mathrm{CdS} /$ Cresyl violet solar cell that showed the lowest value of $J_{\mathrm{sc}}$ of $3.1 \mathrm{~mA} / \mathrm{cm}^{2}$ (Table 1). We observed strong enhancement of the output of the fabricated DSSCs after heat treatment (see Figure 7). The short circuit photocurrent density $J_{s c}$ increased for all prepared solar cells and that could be attributed to enhancement of the contact between the porous $\mathrm{CdS}$ thin films and the dyes. In addition the heat treatment could have caused an increase in the crystallinity of dyes that in turn led to an increase in the $J_{\mathrm{sc}}$ of DSSCs. The power 


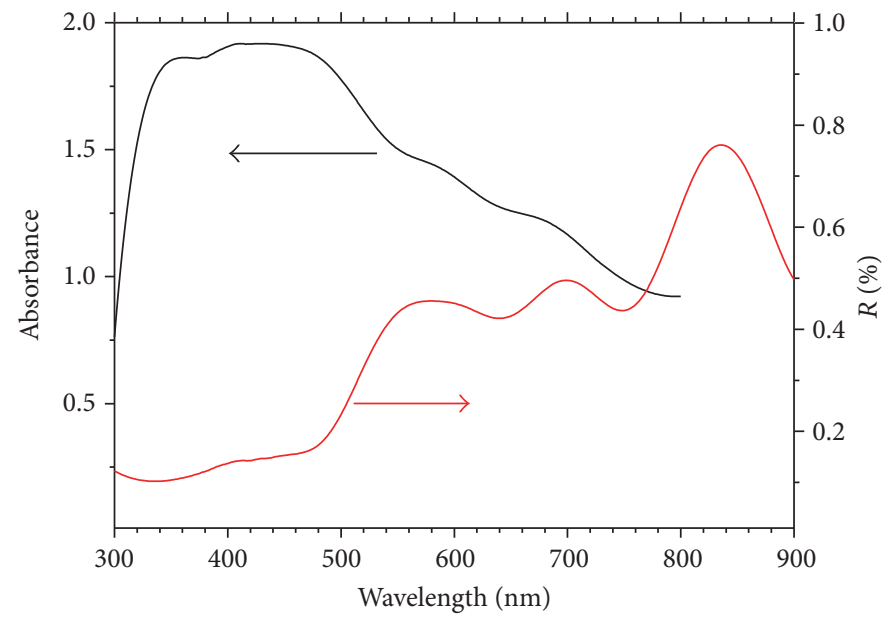

(a)

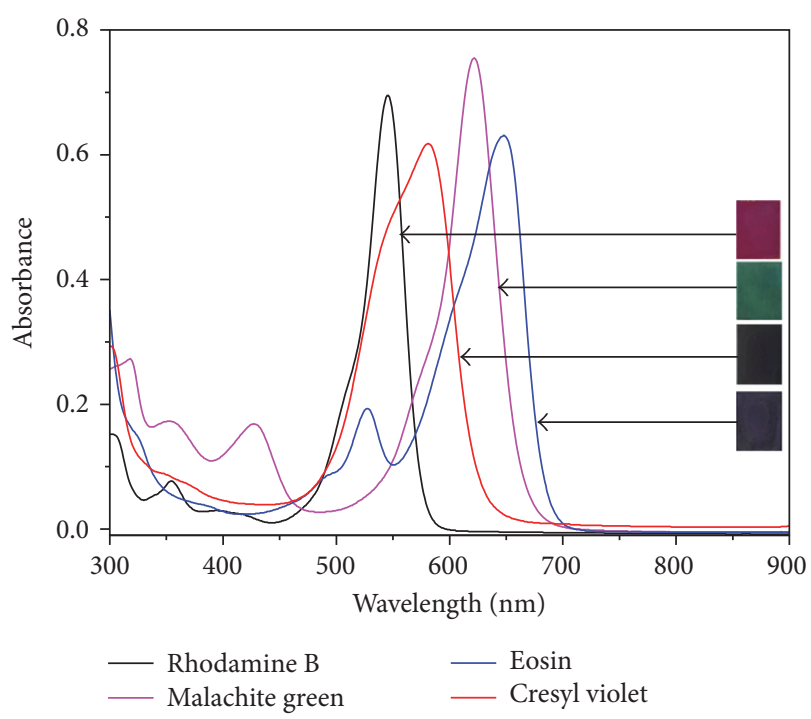

(b)

FIgURE 4: (a) Optical absorbance and reflection of porous CdS nanocrystalline thin film prepared onto FTO/glass substrate, (b) optical absorbance of dyes.

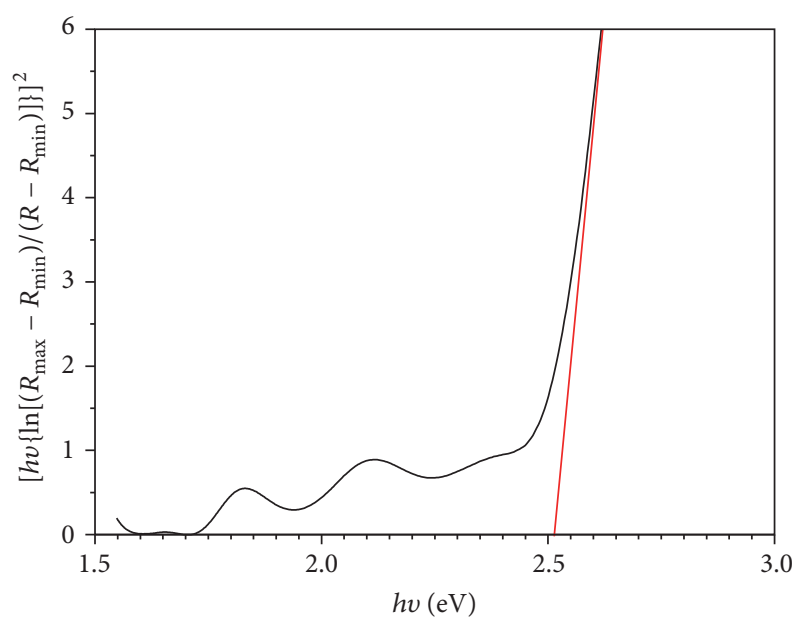

FIGURE 5: Optical band gap determination of porous CdS film from reflection spectra.

conversion efficiencies of the solar cells were calculated using the relationship [24]:

$$
\eta=\left(\frac{J_{m} V_{m}}{P_{\text {in }}}\right) \times 100 \%,
$$

where $P_{\text {in }}$ is the power of the incident light, $J_{m}$ is the current density at the maximum power point, and $V_{m}$ is the voltage at the maximum power point. The fill factor $(\mathrm{FF})$ is calculated using the relationship [24]:

$$
\mathrm{FF}=\frac{J_{m} V_{m}}{J_{\mathrm{sc}} V_{\mathrm{oc}}}
$$

The solar cell that was fabricated using Malachite green dye shows the highest conversion efficiency before annealing

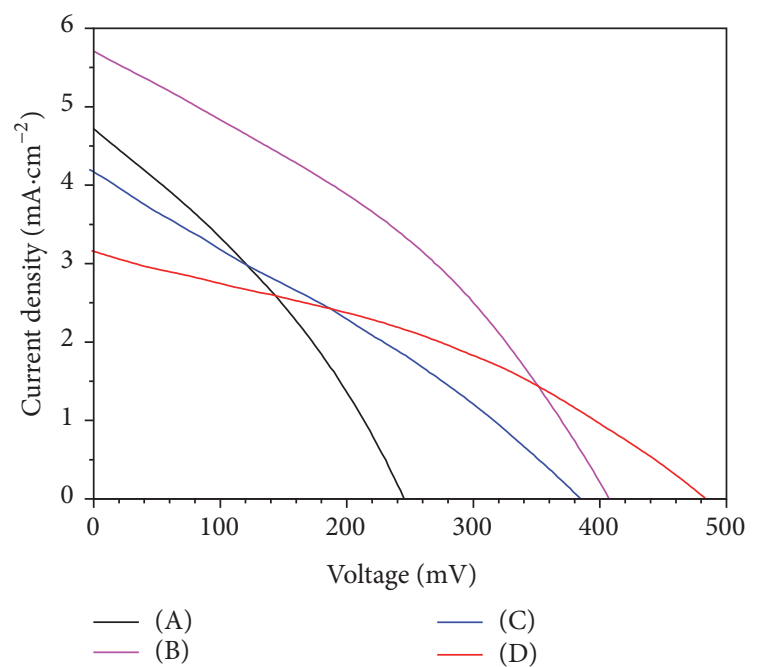

FIgURE 6: $J-V$ characteristics of as-prepared DSSCs (A) porous CdS/Rhodamine B dye, (B) porous CdS/Malachite green dye, (C) porous CdS/Eosin-methylene blue dye, and (D) porous CdS/Cresyl violet dye.

of $0.83 \%$ while that using Rhodamine B dye had the lowest conversion efficiency of $0.38 \%$. All fabricated solar cells show a low value of the fill factor in Table 1 . The main reason for the low conversion efficiencies could be the poor fill factors of the as-prepared DSSC devices. However, the electrolyte type is another important parameter that could affect the value of the FF and $\eta$ of the DSSC. The low value of fill factor may be ascribed to the lower hole recovery rate of the polysulfide electrolyte, which leads to a higher probability for charge recombination [25].

Furthermore, heat treatment of the fabricated solar cells caused significant enhancement in the output of all devices 
TABLE 2: Output of prepared porous CdS nanocrystalline thin films/dyes DSSCs after heat treatment process.

\begin{tabular}{lcccccc}
\hline Dye & Ann. temperature & $J_{\text {sc }}\left(\mathrm{mA} / \mathrm{cm}^{2}\right)$ & $V_{\mathrm{oc}}(\mathrm{mV})$ & $R_{\mathrm{sh}}(\Omega)$ & $R_{s}(\Omega)$ & $\mathrm{FF} \%$ \\
\hline Rhodamine B & $185^{\circ} \mathrm{C}$ & 6.39 & 338.0 & 1617 & 412 & 41 \\
Malachite green & $125^{\circ} \mathrm{C}$ & 7.35 & 414.5 & 2281 & 477 & 37.5 \\
Eosin methylene blue & $90^{\circ} \mathrm{C}$ & 8.67 & 416 & 1312 & 513 & 34 \\
Cresyl Violet & $130^{\circ} \mathrm{C}$ & 6.77 & 447 & 3178 & 435 & 41.5 \\
\hline
\end{tabular}

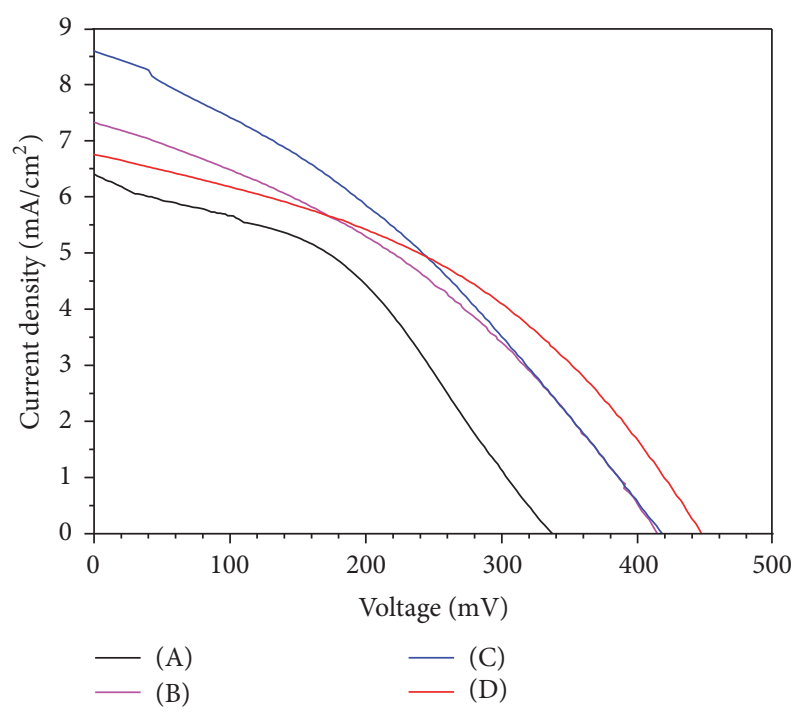

FIGURE 7: $J-V$ characteristics of prepared DSSCs after annealing process (A) porous CdS/Rhodamine B dye, (B) porous CdS/Malachite green dye, $(C)$ porous CdS/Eosin-methylene blue dye, and (D) porous CdS/Cresyl violet dye.

as shown in Table 2 . The $\eta$ of the solar cells fabricated using Rhodamine B, Malachite green, Eosin methylene blue, and Cresyl violet dyes is increased by the ratio of $231 \%, 140 \%$, $230 \%$, and $219 \%$ respectively, after the heating treatment process.

The series resistance $\left(R_{s}\right)$ is another parameter that can affect cell performance and high $R_{s}$ value reduces the output voltage under load, thereby decreasing the FF. Thus $R_{s}$ should be low because increasing the $R_{s}$ of a solar cell increases the voltage drop within the solar cell [24]. The value of $R_{s}$ for all prepared solar cells decreased after heat treatment as shown in Table 1 . At the same time, the shunt resistance $\left(R_{\mathrm{sh}}\right)$ of DSSCs increased after heat treatment for two devices (except for the Cresyl and Eosin solar cells) and that contributed to the increase in the $J_{\mathrm{sc}}$ value.

Decreasing the $R_{s}$ and increasing $R_{\text {sh }}$ could be a main factor that could lead to increases in the FF and efficiency of the solar cells. In addition, surface recombination is another parameter that has a significant effect on the $J_{\mathrm{sc}}$ and $V_{\mathrm{oc}}$ values of DSSC devices. The $V_{\text {oc }}$ of all prepared DSSCs (except for the Cresyl violet device) increased after heat treatment indicating the enhancement of the CdS/dye coupling that led to fast charge injection (electrons) from the dye molecules to the porous CdS nanostructure thin films and then transfer to the FTO substrate with simultaneous transfer of the holes from the dye to the electrolyte.
Sankapal et al. [26] fabricated DSSCs based on the structure FTO/CdS-flat/CdS nanowires/dye using Rhodamine B and Rose Bengal dyes. They obtained $\eta$ of the solar cell prepared using Rhodamine B of $0.12 \%$ while the other one showed $\eta$ of $0.125 \%$. Sun et al. [27] noted that the efficiency of the solar cell based on $\mathrm{CdS} \mathrm{QD}$ with a $\mathrm{TiO}_{2}$ photoanode using polysulfide as electrolyte increased from $0.054 \%$ to $0.22 \%$ when the $R_{s}$ decreased from $218 \Omega$ to $53.8 \Omega$. CdS quantum dots are used to prepare DSSCs with other nanomaterials, especially $\mathrm{TiO}_{2}$. Sun et al. [27] noted that the efficiency of a CdS QD/ $/ \mathrm{TiO}_{2}$ nanotube array increased about 35 times to reach $4.15 \%$ when the CdS QDs are used with $\mathrm{TiO}_{2}$ [27].

\section{Conclusions}

Porous CdS nanocrystalline thin films can be prepared by $\mathrm{CBD}$ onto a FTO/glass substrate. The porous CdS thin films could be structured with cubic phase as concluded from the XRD pattern. Porous CdS/dye solar cells were fabricated using Rhodamine B, Malachite green, Eosin methylene blue, and Cresyl violet dyes. The DSSCs that were prepared using Malachite green dye showed a high conversion efficiency of $0.88 \%$ compared with other dyes while the CdS/Rhodamine B solar cell shows the lowest efficiency of $0.38 \%$. Heat treatment of the fabricated DSSCs led to enhancement of the performance of the output of all devices. The conversion efficiency was increased for CdS/Rhodamine B from $0.38 \%$ to $0.88 \%$ when the device was annealed at $185^{\circ} \mathrm{C}$ for $30 \mathrm{~min}$. However, the maximum efficiency of $1.25 \%$ was obtained from a Cresyl violet solar cell after heat treatment at $130^{\circ} \mathrm{C}$. The enhancement in the output of fabricated DSSCs after heat treatment could be attributed to decreasing the $R_{s}$ and increasing $R_{\mathrm{sh}}$ compared with as-fabricated solar cells.

\section{Competing Interests}

The authors declare that they have no competing interests.

\section{References}

[1] J. H. Yum, T. W. Holcombe, Y. Kim et al., "Blue-coloured highly efficient dye-sensitized solar cells by implementing the diketopyrrolopyrrole chromophore," Nature, vol. 3, pp. 2446-2452, 2013.

[2] B. O’Regan and M. Grätzel, "A low-cost, high-efficiency solar cell based on dye-sensitized colloidal $\mathrm{TiO}_{2}$ films," Nature, vol. 353, no. 6346, pp. 737-740, 1991.

[3] Q. Zhang, Y. Zhang, S. Huang et al., "Application of carbon counterelectrode on CdS quantum dot-sensitized solar cells (QDSSCs)," Electrochemistry Communications, vol. 12, no. 2, pp. 327-330, 2010. 
[4] M. A. Mahdi, Z. Hassan, S. S. Ng, J. J. Hassan, and S. K. M. Bakhori, "Structural and optical properties of nanocrystalline CdS thin films prepared using microwave-assisted chemical bath deposition," Thin Solid Films, vol. 520, no. 9, pp. 3477-3484, 2012.

[5] M. A. Mahdi, J. J. Hassan, Z. Hassan, and S. S. Ng, "Growth and characterization of $\mathrm{Zn}_{x} \mathrm{Cd}_{1-x} \mathrm{~S}$ nanoflowers by microwaveassisted chemical bath deposition," Journal of Alloys and Compounds, vol. 541, pp. 227-233, 2012.

[6] M. Tomakin, M. Altunbaş, E. Bacaksiz, and Ş. Çelik, "Current transport mechanism in CdS thin films prepared by vacuum evaporation method at substrate temperatures below room temperature," Thin Solid Films, vol. 520, no. 7, pp. 2532-2536, 2012.

[7] B. Ullrich, D. Ariza-Flores, and M. Bhowmick, "Intrinsic photoluminescence Stokes shift in semiconductors demonstrated by thin-film CdS formed with pulsed-laser deposition," Thin Solid Films, vol. 558, pp. 24-26, 2014.

[8] A. V. Rao, G. M. Pajonk, and N. N. Parvathy, "Preparation and characterization of nanocrystalline CdS doped monolithic and transparent TEOS silica xerogels using sol-gel method," Materials Chemistry and Physics, vol. 48, no. 3, pp. 234-239, 1997.

[9] H. M. Pathan and C. D. Lokhande, "Deposition of metal chalcogenide thin films by successive ionic layer adsorption and reaction (SILAR) method," Bulletin of Materials Science, vol. 27, no. 2, pp. 85-111, 2004.

[10] M. A. Mahdi, S. J. Kasem, J. J. Hassen, and A. A. Swadi, "Structural and optical properties of chemical deposition CdS thin films," International Journal of Nanoelectronics and Materials, vol. 2, pp. 163-172, 2009.

[11] M. A. Mahdi, A. Ramizy, Z. Hassan, S. S. Ng, J. J. Hassan, and S. J. Kasim, "CdS nanocrystalline structured grown on porous silicon substrates via chemical bath deposition method," Chalcogenide Letters, vol. 9, no. 1, pp. 19-25, 2012.

[12] A. S. Obaid, M. A. Mahdi, Z. Hassan, and M. Bououdina, "Preparation of chemically deposited thin films of $\mathrm{CdS} / \mathrm{PbS}$ solar cell," Superlattices and Microstructures, vol. 52, no. 4, pp. 816-823, 2012.

[13] M. F. Hossain, S. Biswas, and T. Takahashi, "Study of CdSsensitized solar cells, prepared by ammonia-free chemical bath technique," Thin Solid Films, vol. 518, no. 5, pp. 1599-1602, 2009.

[14] S. S. Mali, R. S. Devan, Y.-R. Ma et al., "Effective light harvesting in CdS nanoparticle-sensitized rutile $\mathrm{TiO}_{2}$ microspheres," Electrochimica Acta, vol. 90, pp. 666-672, 2013.

[15] H. Choi, R. Nicolaescu, S. Paek, J. Ko, and P. V. Kamat, "Supersensitization of CdS quantum dots with a near-infrared organic dye: toward the design of panchromatic hybrid-sensitized solar cells," ACS Nano, vol. 5, no. 11, pp. 9238-9245, 2011.

[16] Y. Meng, Y. Lin, Y. Lin, and Y. Wang, "Dye modification with photovoltaic enhancement for CdS quantum dots sensitized solar cell based on three-dimensional $\mathrm{ZnO}$ spheres," Journal of Materials Science: Materials in Electronics, vol. 25, no. 7, pp. 3034-3038, 2014.

[17] S. R. Gosavi, C. P. Nikam, A. R. Shelke et al., "Chemical synthesis of porous web-structured CdS thin films for photosensor applications," Materials Chemistry and Physics, vol. 160, pp. 244-250, 2015.

[18] M. Grätzel, "Dye-sensitized solar cells," Journal of Photochemistry and Photobiology C: Photochemistry Reviews, vol. 4, no. 2, pp. 145-153, 2003.
[19] R. Swanepoel, "Determination of the thickness and optical constants of amorphous silicon," Journal of Physics E: Scientific Instruments, vol. 16, no. 12, pp. 1214-1222, 1983.

[20] Y.-L. Lee and C.-H. Chang, "Efficient polysulfide electrolyte for CdS quantum dot-sensitized solar cells," Journal of Power Sources, vol. 185, no. 1, pp. 584-588, 2008.

[21] V. Kumar, S. K. Sharma, and D. K. Dwivedi, "Crystallographic, optical and electrical properties of low zinc content cadmium zinc sulphide composite thin films for photovoltaic applications," Journal of Alloys and Compounds, vol. 512, no. 1, pp. 351354, 2012.

[22] M. A. Mahdi, J. J. Hassan, S. S. Ng, and Z. Hassan, "Growth of CdS nanosheets and nanowires through the solvothermal method," Journal of Crystal Growth, vol. 359, no. 1, pp. 43-48, 2012.

[23] M. A. Mahdi, J. J. Hassan, S. J. Kasim, S. S. Ng, and Z. Hassan, "Optical properties of CdS micro/nanocrystalline structures prepared via a thermal evaporation method," Materials Science in Semiconductor Processing, vol. 26, no. 1, pp. 87-92, 2014.

[24] H. F. Al-Taay, M. A. Mahdi, D. Parlevliet, and P. Jennings, "Fabrication and characterization of solar cells based on silicon nanowire homojunctions," Silicon, vol. 9, no. 1, pp. 17-23, 2017.

[25] C. Liu, Y. Li, L. Wei et al., "CdS quantum dot-sensitized solar cells based on nano-branched $\mathrm{TiO}_{2}$ arrays," Nanoscale Research Letters, vol. 9, no. 1, pp. 107-115, 2014.

[26] B. Sankapal, A. Tirpude, S. Majumder, and P. Baviskar, "1D electron path of 3-D architecture consisting of dye loaded CdS nanowires: dye sensitized solar cell," Journal of Alloys and Compounds, vol. 651, pp. 399-404, 2015.

[27] W.-T. Sun, Y. Yu, H.-Y. Pan, X.-F. Gao, Q. Chen, and L.M. Peng, "CdS quantum dots sensitized $\mathrm{TiO}_{2}$ nanotube-array photoelectrodes," Journal of the American Chemical Society, vol. 130, no. 4, pp. 1124-1125, 2008. 

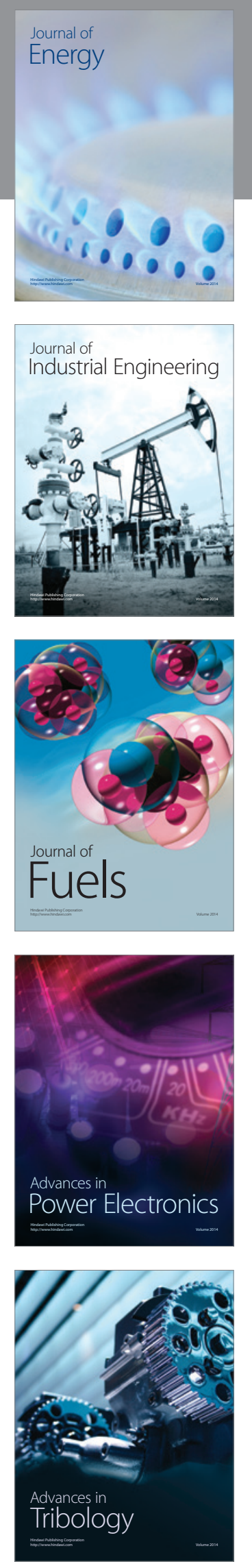
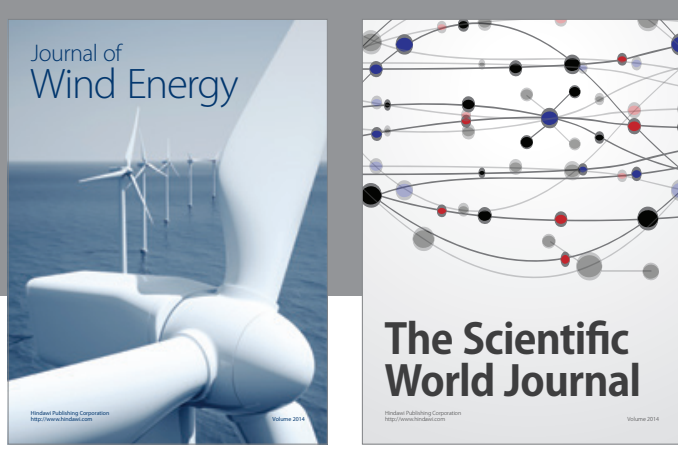

The Scientific World Journal
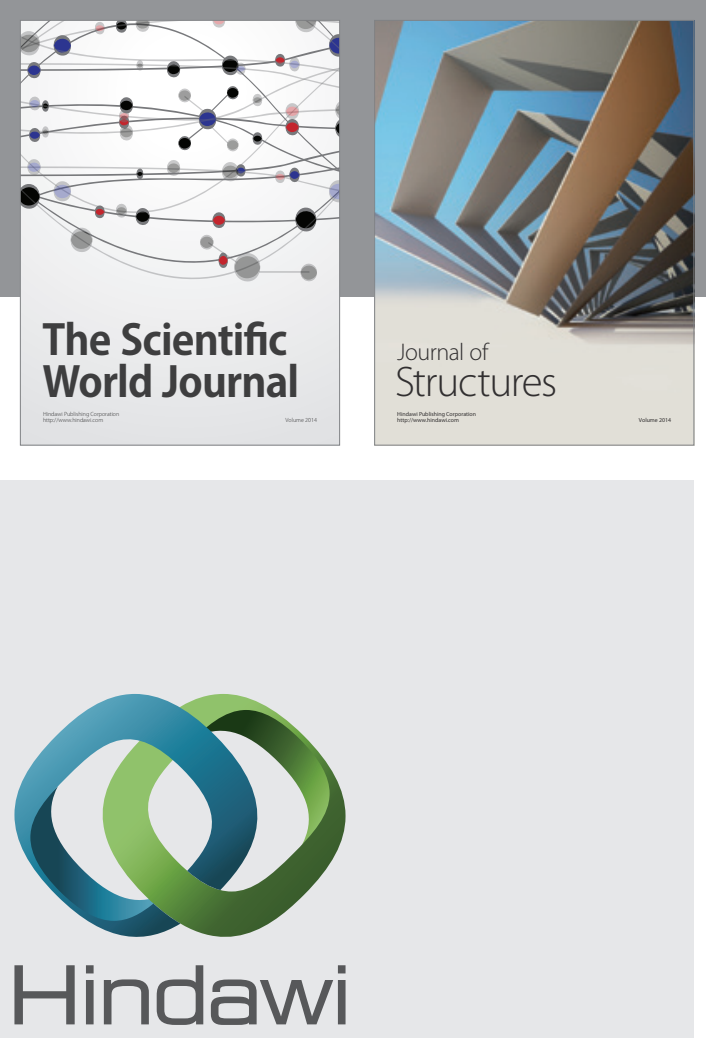

Submit your manuscripts at

http://www.hindawi.com
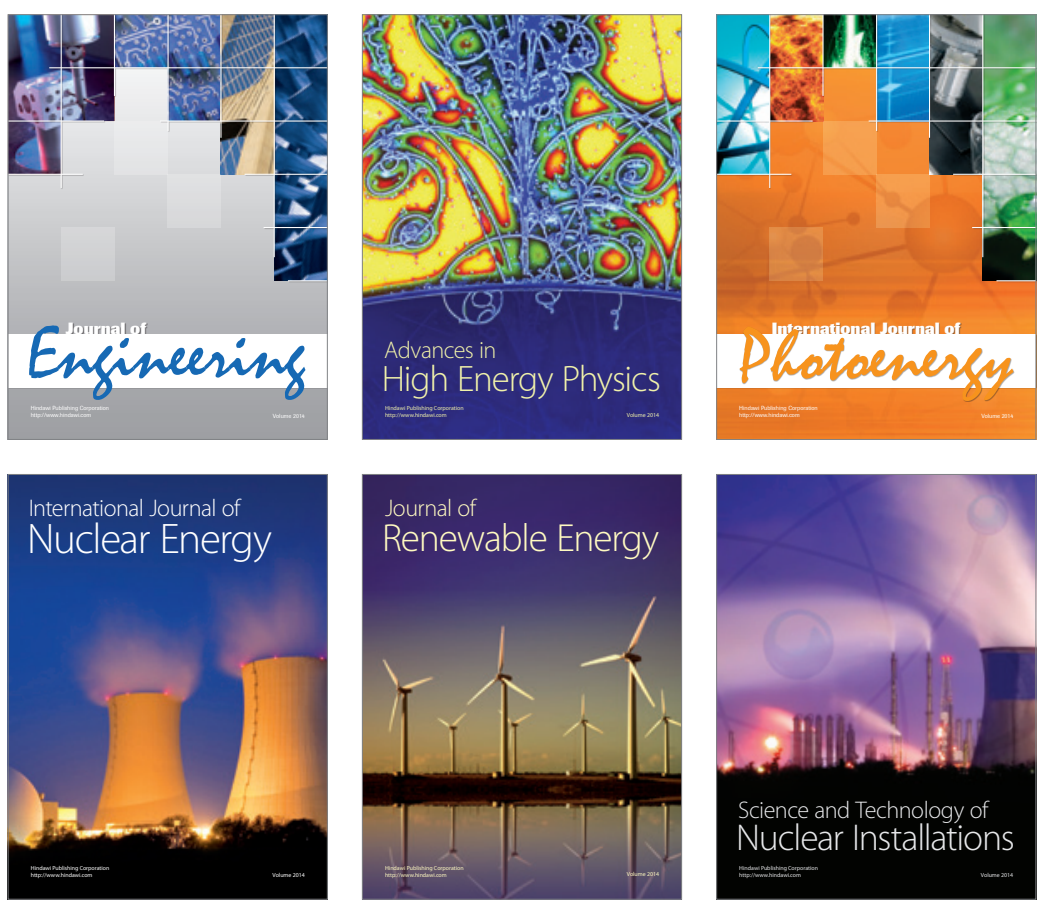
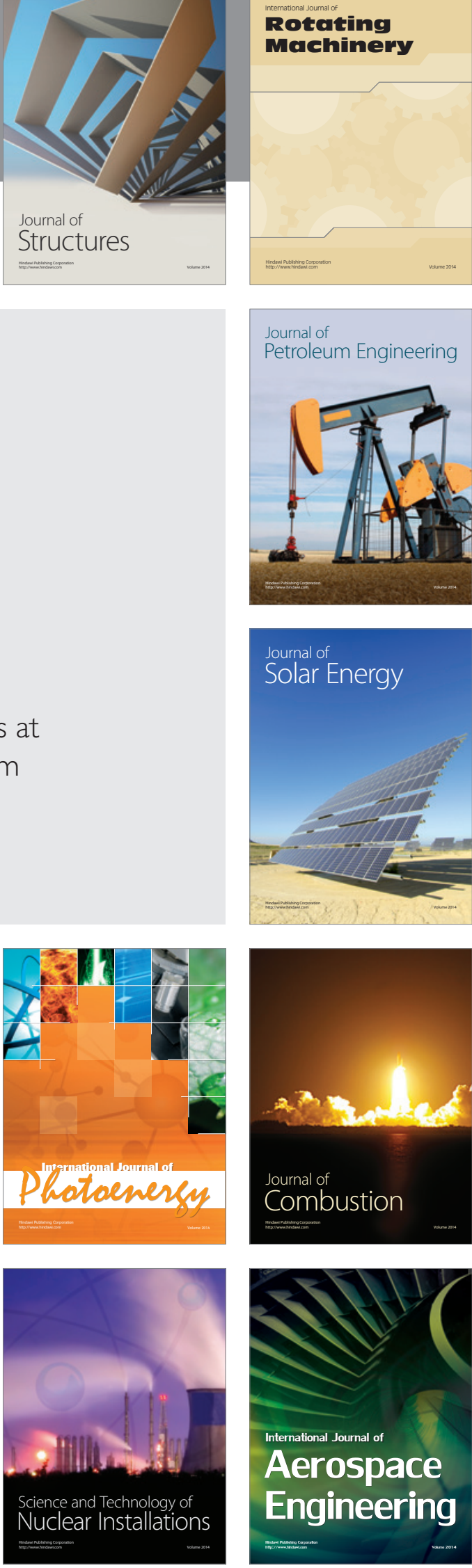